Discourse and Communication for Sustainable Education, vol. 7, no. 2, pp. 17-33, 2016

\title{
Culturally Responsive Dispositions in Prospective Mathematics Teachers
}

\author{
Desha L. Williams \\ Kennesaw State University, the United States \\ Belinda Edwards \\ Kennesaw State University, the United States \\ Karen A. Kuhel \\ Kennesaw State University, the United States \\ Woong Lim \\ University of New Mexico, the United States
}

\begin{abstract}
Sustaining teachers in culturally and linguistically diverse schools has been a prominent issue for years. This qualitative study focused on the impact of an enhanced preparation program on the cultural dispositions of five pre-service mathematics teachers. It is postulated that if positive cultural dispositions are developed in teacher candidates, the possibility of them remaining in cultural school settings is likely. Themes emerged demonstrating that the enhanced program heightened the participants' awareness of cultural and linguistic differences, as well as, their commitment to impacting academic achievement. Of the five participants, four teach in a culturally and linguistically school after five years in the profession, demonstrating sustainability after participating in the enhanced program.
\end{abstract}

Keywords: teacher preparation, teacher sustainability, teacher retention, cultural dispositions, mathematics teacher preparation

In many culturally and linguistically diverse (CLD) school settings, teachers' retention and attrition is at an all-time high (Ingersoll, Merrill, \& Stuckey, 2014; National Center for Education Statistics [NCES], 2016). The lack of teacher retention may have a negative impact of student achievement and learning efficacy (Gershenson, Holt, \& Papageorge, 2016). Students are left with feelings of abandonment, impacting their academic potential (Martin, 2009). Creating a sustainable workforce prepared to teach CLD students is paramount, particularly in the STEM fields. The number of CLD diverse students pursuing STEM fields at colleges and universities fall extremely short when compared to their White counterparts (Nation Assessment of Educational Progress [NAEP], 2015). 
In preparing teachers for sustained employment in CLD schools, preparation programs must prepare them to be attentive to the needs of all students and create equitable, inclusive, and supportive environments, which include communicating high expectations for academic achievement.

Critical to becoming an effective mathematics teacher for diverse learners is a combination of content knowledge, dispositions, and pedagogical knowledge that will support students' mathematical thinking and learning as well as their home culture and funds of knowledge (Gay, 2000, Lucas, Villegas, \& Freedson-Gonzalez, 2008). However, prospective teachers are underprepared to teach mathematics effectively in diverse classrooms (Garcia, Arias, Harris Murri, \& Serna, 2010; Jenks, Lee, \& Kanpol, 2001). Teacher preparation programs have been found to be effective in ensuring perspective teachers are equipped with appropriate mathematical content knowledge and general pedagogical strategies. However, research suggests that teacher preparation programs have done little to prepare teachers to work with CLD children (Arias \& Poynor, 2001; Darling-Hammond \& Bransford, 2007; Garcia et al., 2010; Jenks et al., 2001). Studies have been published indicating that teachers are not adequately prepared to teach CLD students and have little knowledge of culturally responsive teaching (CRT) and learning strategies (Blanchett, 2006; Jones \& Fuller, 2003; Lucas \& Villegas, 2007). Hayes and Juirez (2012) claimed that White racial domination still occurs in teacher education and this impedes the preparation of teachers for CRT. Similarly, studies of prospective teachers' cultural awareness have found that prospective teachers in both North America (Larke, 1990) and Hong Kong (Yeung, 2006) report feelings of discomfort when working with students from CLD backgrounds.

Gay (2000) cited a disparity between theory and practice, suggesting that teachers can indeed have the disposition to teach to diversity; however, dispositions of the teachers quite often do not align with the theories supporting CRT. In light of the need to examine prospective teachers' ways to integrate theory and practice of CRT, we note that the current literature regarding the dispositions of prospective teachers is limited (Edwards, 2011). Extending the line of work regarding the dispositional issues of cultural responsiveness (Edwards, 2011), this case study aimed to consider the dispositions related to developing culturally responsive mathematics teachers. Findings from the study can add to the knowledge base with regard to how cultural dispositions impact the teaching and learning environment. The research question that guided this study was: To what extent does a program, designed to prepare teachers to effectively teach CLD students, impact the cultural dispositions of prospective mathematics teachers? It is the authors' views that teachers who possess positive cultural dispositions will have the necessary dispositions to impact student learning and be sustained in CLD school settings (Banks \& Banks, 2009).

\section{Theoretical Framework}

There have been numerous ways to conceptualize the characteristics of an effective classroom teacher, including how teachers develop those characteristics. Dewey (1933) found that effective teachers are open-minded, act responsibly, and take initiatives in creating engaging lessons. Later, Haberman (1995) claimed that effective urban teachers seek resources to meet the diverse needs of their students and are persistent and inventive in engaging students who may be resistant to academic engagement. Additionally, effec- 
tive teachers are reflective in an effort to improve practice and draw upon studentteacher relationships to create relevant lessons.

In order to make sense of these ideas on a spectrum, we incorporated the theory of the functioning of teacher dispositions and the role of teacher education in developing awareness (Stookberry, Schussler, \& Bercaw, 2009) with Dewey's and Haberman's views of the characteristics of effective teachers. Teacher candidates enter a teacher preparation program with a variety of life experiences and socializations in schools (Kabadayi, 2015). The theory of the functioning of teacher dispositions and the role of teacher education (Stooksberry, Schussler, \& Bercaw, 2009) postulates that the teacher education program provides an awareness that either challenges or supports the candidates' assumptions, inclinations, and dispositions, and that candidates ultimately emerge with various behaviors and thinking (see Figure 1). Examining the characteristics presented by Dewey and Haberman within the data through the lens of the theory of the functioning of teacher dispositions, along with the role of teacher education, provides a mosaic theoretical framework that takes into account the underlying qualities of effective teachers while recognizing the uniqueness of the urban environment, where many CLD learners reside. This enables the examination of developing dispositions of prospective teachers who are engaged in a teacher preparation program but do not actually have their own classroom to transform their dispositions into action.

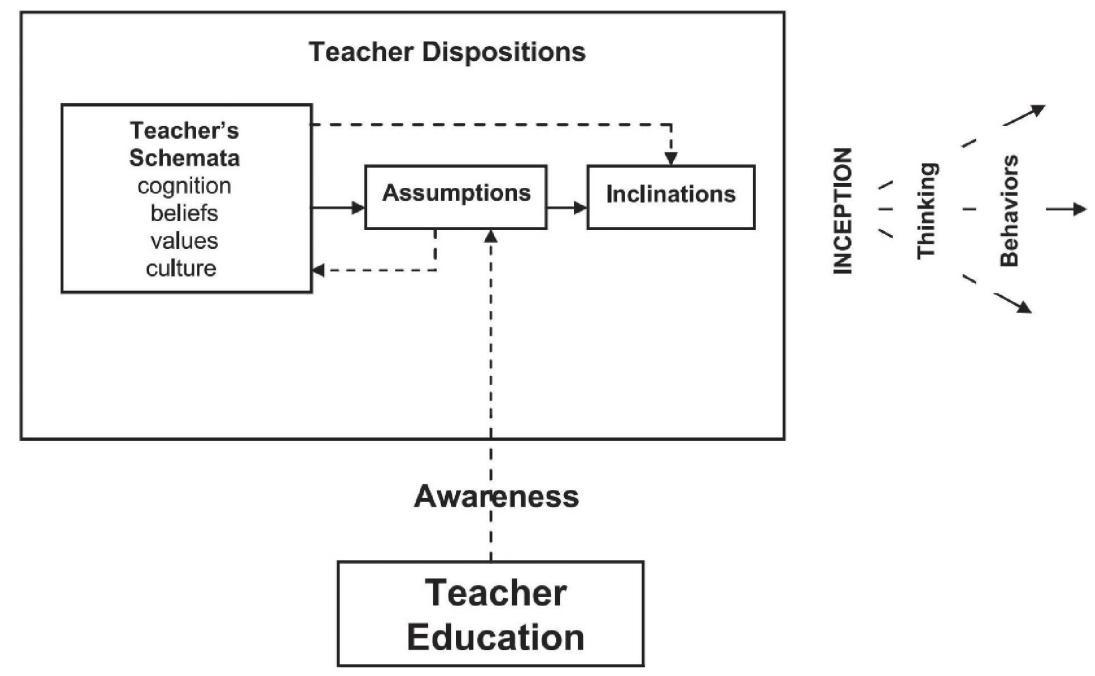

Figure 1. The Development of Teacher Dispositions and the Role of Teacher Education in Promoting Awareness (adapted from Stooksberry, Schussler, \& Bercaw, 2009, p. 722).

\section{Relevant Literature}

This study examined the changes in dispositions of prospective teachers, in particular those who have made the conscious decision to teach CLD learners. We reviewed the research regarding teachers' dispositions, affective experiences for meaningful change, affective issues with mathematics, and dispositions toward cultural diversity among prospective mathematics teachers. 


\section{Cultural Dispositions}

Cultural dispositions are "teachers' inclination to meet the needs of the diverse learners in the classroom" (Schussler, Bercaw, \& Stooksberry, 2008b, 107). There is evidence that cultural dispositions play a significant role in ensuring that teacher culture and student culture co-construct opportunities for learning (Banks, Cochran-Smith, Richert, Zeichner, LePage, \& McDonald, 2005; Schussler et al., 2008; Splitter, 2010; Gerretson, Iliško, \& Fortino, 2010). However, in reality, teachers often enter school or classroom environments where the culture of their students does not align with their own and, in some cases, this can lead to a learning environment that lacks inclusiveness and relevance, and hinders students' participation in classroom activities (Hertzig, 2005).

\section{Affective Attributes}

Teacher candidates should reflect on their thinking and actions to develop an awareness of their dispositions, we believe affective experiences have the potential to foster the development of appropriate dispositions. Research suggests that affective views could be stored in episodic memory, rooted within one's personal experiences, thus not allowing to access one's affective qualities through questioning or logical analysis (Nespor, 1987). This gives more credence to the view that a thoughtful and purposeful approach to developing affective responses is necessary; and Harrison (2008) called for more research about ways to develop affective qualities in higher education. Grootenboer (2010) suggested that students be placed in a field experience with the intent to increase opportunities for authentic experiences unlike content learning in lecture halls on campus, and that the professional programs provide learning experiences carefully designed to develop affective attributes as important part of components in the coursework.

\section{Affective Issues with Mathematics}

Mathematics has not produced the same amount of research in affective issues as some other disciplines, such as social science, language, and literature studies (Allchin, 1999; Aplin \& Saunders, 1996; Lee \& Cockman, 1995). Even though mathematics has been viewed as a value-free and culture-free discipline (Bishop, FitzSimons, Seah \& Clarkson, 1999), researchers (e.g., Bishop, 1998; D’Ambrosio, 2001) have found that culture plays a pivotal role in the teaching and learning of mathematics. Grootenboer (2010) claims that the rich tradition of beliefs and values about mathematics teaching and learning should be examined. The underlying dispositions towards mathematics and the professional practice of teaching should be part of active field research in order to attend to pedagogical approaches that develop students' affective qualities.

\section{Dispositions Toward Cultural Diversity}

Giles \& Sherman (1982) defined cultural diversity as related to the ways people perceive differences in skin color, language use, and socioeconomic status from the middle-class Anglos. Dee and Henkin (2002) reported that educator's attitudes towards pluralism and diversity could be understood in a more systematic way. For example, Dee and Henkin found that some educators are more likely to include diversity in content, 
value equity in the classroom, and feel comfortable interacting with those with different cultural backgrounds. Those educators recognize diversity as positive for society and understand how assimilation to the mainstream culture contributes to people's success in society.

The field has recognized that knowledge of students is a critical component of teacher knowledge (Shulman, 1987); however, teachers are not adequately prepared to teach students with diverse backgrounds (National Center for Education Statistics, 1999). Multiple studies reported that teachers have cultural lenses that are significantly different from those of racial and ethnic minority students (Gillette \& Boyle-Baise, 1995; Paige, 1993; Rios, 1996). Irvine (1990) argued that such a gap between the teacher and minority students could produce a variety of negative results such as inappropriate remediation, harsh discipline, and attributing minority students' academic and classroom behaviors to their home environment.

Over time, there has been a growing body of literature that supports the view that teacher education should facilitate pre-service teachers' learning to explore beyond the familiar boundaries of cultural norms and to overcome ambiguities and psychological risks associated with cultural dispositions. For example, one study (Villegas, 2007) reports a case in which a teacher preparation program facilitated pre-service teachers' learning so that they become aware how they respond in the classroom to CLD children. Bennett (2008) examined pre-service secondary teacher development for teaching students who live in economically disadvantaged situations. The results found that after participating in a driving tour, reading literature, and writing a reflection paper the participants developed (a) an of awareness of socioeconomic differences, (b) empathetic rapport and caring attitudes, and (c) a commitment to CRT. So will the immersion in a variety of cultural, linguistics, and content experiences have an increased impact?

\section{Methodology}

The participants of this study were enrolled in a traditional Master's of Arts in Teaching degree program at a large state university with specific field placements in CLD schools. Additionally, participants attended monthly seminars and professional conferences that focused on various aspects of teaching in CLD schools.

Five students participated in this qualitative case study. The study of Danielle, Amber, Linda, Erin, and Janice is bounded by the preparation program and being recipients of a scholarship that focused on preparing teachers for CLD student populations (Merriam, 2001). The participants were Caucasian women ranging in ages from 24 to over 50. Danielle, Amber, Erin, and Janice are career changers. Linda began the program directly upon completion of her undergraduate degree.

\section{The Experiences}

The participants attended five workshops, each with a unique focus. The first workshop focused on teaching mathematics for ELs. The participants read literature on the subject prior to the workshop. Strategies along with potential challenges were shared in the two-hour workshop. The second workshop gave the participants the opportunity to interact with veteran teachers of ethnically and economically diverse students. The veteran teachers shared their experiences with race, culture, or gender in classrooms, 
schools, and communities, and answered questions. The third workshop placed participants in a simulation in which some experienced being in a position of power and privilege while others in a marginalized position. The participants also read literature on the use of the tenets of social justice in mathematics instructions. The fourth workshop gave participants a glimpse into the lives of students who are homeless, the impact of homelessness on schooling, and legislation protect students who are homeless. The final workshop demonstrated various pedagogical strategies to meet the needs of various learners including the effective use of manipulatives in secondary mathematics classrooms and provided presentation on research-based practice to create differentiated environments.

In addition to the workshops, participants attended two of three conferences. All of the participants attended a regional conference with other mathematics and science scholars. This conference gave participants an opportunity to network with peers and other education professionals. Participants chose to either attend the state's mathematics conference or attend a state-level EL conference. The state mathematics conference was a two-day conference of concurrent sessions on various topics of pedagogies and other issues impacting mathematics and mathematics education in the state. The EL conference was similar except the focus is on the pedagogies of effective lessons for teaching ELs.

\section{Methods of Data Collection and Analysis}

Multiple sources of data were used to allow for triangulation of findings. Data sources were entry and exit interviews, and five workshop questionnaires. Data were collected over a period of 4 semesters. Entry interviews were used to gather baseline data regarding participants' dispositions for working with diverse populations, their openness to providing rigorous, equitable mathematics opportunities for ALL students. An example question is, "Standardized test scores of some ethnically and linguistically diverse student groups have fallen short. Provide one reason you believe this is occurring and can you offer a possible solution." Another example is, "Do you believe today's schools are equitable? If not, provide an example of how are they not equitable. If they are equitable, why do you believe this?" Each of the workshop questionnaires focused on the workshop's topic. The questionnaires were designed to gather insight on participants' views before and after the workshop. An example of a workshop question is, "Is there a difference in teaching students who are economically disadvantaged than those who are not?" Another example is "Should teachers use pedagogies of teaching for social justice in mathematics instruction? Why or why not?" A follow-up questions examined how the participates would describe a lesson from a social justice perspective. In exit interviews, similar questions explored in the entry interview and in questionnaires throughout the program were revisited. This was done to determine if participants' dispositions in these areas had remained or were altered in any way.

Data were examined at various stages (beginning, middle, and end) of the program and reexamined collectively using open and axial coding (Strauss \& Corbin, 1990). During the open coding stage of analysis, researchers carefully read, each response to the entry and exit interview questions, as well as, the workshop questionnaire responses. Our goal was to discover and categorize the data into specific ideas, concepts, and topics of discussion that were related to the research question and other related viewpoints. Each researcher independently coded the data, assisting with reliability of the data. A 
team meeting was held to compare and develop a unified coding scheme. We examined participants' knowledge prior to participating in various seminars and workshops and how that knowledge shaped their dispositions, paying particular attention to their awareness of cultural factors, including their openness and dispositions towards students' culture in regards to teaching and learning. In summary, our analysis of data revealed three important components related to participants' dispositions prior to entering, during, and at completion of the program.

\section{Findings}

The findings are presented in three components: Dispositions upon entrance into the program, during program, and at the completion of the program.

\section{Dispositions Upon Entrance Into the Program}

Two themes emerged in the analysis of the data upon entrance into the program: equity awareness and deficit awareness. Equity Awareness is defined as a desire for equity, recognition of inequitable practices, a desire to advocate for students, and the optimism in accomplishing their advocacy efforts. Deficit Awareness is described as critiquing the act of placing blame for failure in school on the child and/or family.

All participants were aware of equity differences in school for various reasons. Amber noted that the quality of education varies depending upon school location, "Good schooling depends on where you live. Best teachers go to school with better kids." Danielle realized that tests were culture biased, "Test should not be design for the culture we are." Amber noted that if the culture of a school was not responsive to the needs of CLD students that a teacher may have to stand up for that child, "If [the decision] was extreme, I would fight for [the student]."

With regard to deficit awareness, the data were more complex. While all participants indicated that deficit thinking about students was negative in their entrance interviews, the way they represented this thinking was on a continuum. For example, Janice and Linda focused on differences about students from minority heritages or lower socio-economic backgrounds. "Students' backgrounds are the reason for shortcomings in achievement testing for minority students" (Janice). "Kids become self-fulfilling prophecy [in regards to why they struggle]" (Linda). Erin talked about how teachers do not make an impact in academic learning, “Teachers don't differentiate enough. They need to change activities and help students want to learn math.”

\section{Dispositions During Program}

Data collected from questionnaires completed after each of the five workshops generated four themes: In it for the Students, Cultural/Linguistic Responsiveness, Recognition of Areas of Improvement, and Awareness of Differences. Participants showed evidence of empathy, adaption, culturally responsive support for students, a desire to be advocates, and an understanding of the importance of communication. Comments demonstrated participants' passion for serving CLD students.

In it for the students. Participants showed a desire to make a difference in the lives of CLD students. They realized that they had responsibilities as teachers that went 
beyond teaching mathematics. Amber spoke of being aware of school culture and being willing to reach out for assistance, "Be aware of behavior and conditions at school. Be prepared to help [students] and seek help from others [teachers] when appropriate." Erin stated that she could only control her own classroom environment, "Provide security for students inside my classroom and offer to let them stay after school while I'm working." Janice noted that she had learned the importance of communication, "Keep parent contact and communication open." Amber expressed a dilemma and a need to know more about how to be an advocate, "How can I advocate for [homeless students] without making them feel embarrassed about their situation."

Cultural/linguistic responsiveness. Participants understood the need to teach in a culturally and linguistically responsive manner. Linda stated, "Understand the background of my students in order to create culturally relevant math problems." Janice said, "To empower our students, they need to see how math can help our students against social justice issues. I want my students to be successful citizens of the world." Danielle wondered how she could help students see beyond their current context. "How do I get students to realize the importance of being life-long learners?"

Recognition of areas of improvement. There was an overall recognition by participants of being at the beginning of their journey as teachers of CLD learners. "I feel like I could use more exposure in this [economically disadvantaged] area...If I was placed in an inner city low-income majority students, I would probably feel overwhelmed" (Janice). "I need to learn activities [for ELs]" (Danielle). "Let go of pet peeves [to focus on student learning]" (Linda). "I feel that I could use more exposure and knowledge about different cultures. I feel more comfortable with certain ethnic students - Black, Hispanic than maybe others" (Janice).

Awareness of differences. Participants understood that differences impacted the lives of their students and their lives as teachers. Danielle questioned decisions that she made, "As a White woman, who has a totally different concept of necessities, why should I judge? Do I have the right to judge?" Linda reflected on the need to keep the privacy of homeless students in her classroom, "I need to make myself aware of [the impact of homelessness on schooling] as soon as possible and immediately work to keep homeless information secret from other students in my classroom." Janice considered the need to make learning relevant to her students' lives, "Differences in how and what can be used in the classroom with things that are applicable to their lives".

\section{Dispositions at the Completion of the Program}

Three themes emerged at the completion of the program: Cultural/Linguistic Responsiveness, Discovering Differences, and Interpersonal Awareness. Additionally, each theme was analyzed to produce sub-themes.

Cultural/linguistic responsiveness. Participants exhibited positive change in their understanding of culture and how cultural responsiveness impacts teaching and learning. In particular, participant responses indicated two main sub-themes: high expectations and connections.

High expectations. Erin noted that it is important to, "get everybody on a common group to build them up, and to have them excel, beyond what's required of them to help them meet expectations." Linda reflected on the fact that she may not have assumed high expectations for all students when she entered the program, "I've used what I've 
learned from the workshops to rethink my expectations and to differentiate instruction.” Danielle expressed surprise that her students only saw one path to college and that was through the military.

I have so many students who are seniors this year and [they say], "I have to go into the military because that's the only way I can pay for college." I'm like, oh my gosh, there's so much money out there for you. I'll belp you investigate.

Connections. Participants realized the importance of making connections with their students. Erin noted that, "[I] modify and differentiate my lesson in ways that will not only allow me to increase their learning potential." Amber found that:

I do a lot of getting to know my students, their personalities, their interests, their backgrounds, and their ability level both mathematically and with language. I use that information to modify and differentiate my lessons in ways that will not only allow me to increase their learning potential, but keep theirs.

In the final semester of the program, Amber had English learners (EL) in her classroom. Here is how she made connections with her students who did not want to speak English in class.

I think a lot of it comes from the insecurity to speak English, 'well I am not going to speak a language because that's not what I am, I am Hispanic so I am going to speak Spanish' so I said 'okay so you can't do both.' ... okay math is the primary language that I am here to speak or to teach, maybe [teaching] language will be the secondary aspects. So ever since I start letting it be more of bilingual kind of atmosphere. It has been more relax.

Linda noted that teachers who are different from the children they teach need to reach out to better understand their students.

Statistics show that most of the teachers that come in [to teach in a Title I school] don't come from that kind of environment so there is a certain disconnection, so they don't really understand where those kids are really coming from, they don't understand how to connect with them, so that makes it even harder.

Discovering differences. Participants noted differences in two areas: cultural and linguistic differences and differences in societal influences.

Cultural and linguistic differences. Participants became aware of the impact of differences in home culture and how these differences can impact the schooling environment. Erin noted that,

A lot of factors go into why students perform the way they do. I had a lot of students sleep in class or look tired...it opened my eyes to what students go through and how it impacts them in school. If a lot of things are going on at home, it's hard for them to focus in school.

Danielle discovered that, "The hardest thing for me to realize is they're [English learners] not being disrespectful. They're not being rude it's just who they are." 
Linguistics was another area where participants noted differences. As shown in an earlier quote, Amber realized that English learners were not going to automatically speak English in her class and that she had to come to terms with the situation. Amber also noted that she learned, "Some days, they [English learners] get fatigue really quickly dealing with all the language."

Differences in societal influences. Danielle noted the differences between her son's high school education and that of her students at the Title I school where she teaches,

... as a new teacher I try not to judge anything. So when teachers tell me they don't have support at home, I am not going to be believe it until I know it to be true. All I know is that my son goes to a high school [in an affluent area, and they recommend that he [gets extra support outside of school], I didn't get a choice. I knew that my son has to have [that] or he would not be able to keep up in the classroom. Here there is no way you can ask students/parents to provide that and [my Title I high school] doesn't have the resource to provide that for them.

Interpersonal awareness. Interpersonal awareness focused on three sub-areas: reflective, responsibility, and equity.

Reflective. Danielle found that her students are teaching her in a variety of ways, "They are teaching me to be patient, to be kind, to be generous." She also found that she "...needs to be more cognoscente of vocabulary, and not just because of another language, but there is teenager language."

Responsibility. Responsibility was part of each participant's interpersonal awareness. Danielle realized that she needed to make connections, but it took a lot of time. "Oh I'm going to have to find a way you make that connect. And I just do research, it's a lot of work (laugh). Yeah it's a lot of work." Linda came to realize that it is her responsibility to differentiate instruction. "A strong EL...he still wasn't doing well on test. What I mean is this kid knows calculus in the eighth grade. He was doing integrals on the board. I said, 'Obviously I have to make this accessible to him'." Janice also came to the conclusion that she had to change her method of teaching for English learners. "my method to my goals changes...different ways to teach diverse students...use of manipulatives and visual aids, doing word walls and concentrating on vocabulary..." Additionally with regard to differentiation, Amber stated, "I try to make it [lesson] into a game whenever possible... [the mathematics] stays with them longer and it gives them something to reference".

Equity. As with success, equity is difficult to tease out because it is embedded in many of the quotes already used as evidence. But it was evident that all participants agreed with the statement that all children can be successful in school with the right kind of assistance.

\section{Discussion and Conclusion}

The purpose of this study was to examine to what extent does a program, designed to prepare teachers to effectively teach cultural and linguistically diverse students, impact the cultural dispositions of prospective mathematics teachers. Understanding how a specialized program can impact cultural dispositions of pre-service teachers may provide a starting point for increasing sustainability in CLD schools. Overall, our findings were 
similar to that of Bennett (2008) regarding teaching learners from lower socio-economic backgrounds. Findings indicated that critical experiences in teacher education impacted prospective teachers' dispositions towards teaching CLD learners. Monthly seminars and professional conferences focused on cultural responsiveness, teaching for social justice, teaching students who are homeless, mathematical differentiation, and teaching mathematics to English learners positively impacted the participants' cultural dispositions and diversity and interpersonal awareness. Furthermore, the field experience played an integral role in the participants' development of cultural dispositions. It provided opportunities for the participants to make connections with their students that led to differentiation, and culturally responsive lessons.

Our findings also indicate that pre-service teachers whose cultural dispositions are developed tend to embrace diversity and are reflective in their practice as it relates to creating a learning environment that is equitable. According to Schussler et al. (2008a), teachers who have the inclination to reflect on cultural norms and those of their students tend to address the needs of their students. This supports the need to produce effective mathematics teachers for CLD learners by preparing prospective teachers who have dispositions that support students' mathematical thinking and learning as well as their home culture and funds of knowledge (Gay, 2000).

Some critics say examining pre-service teachers' dispositions may “detract from the real work of giving teachers-to-be the knowledge and skills needed to teach their future students" (Villegas, 2007, p 370). However, beliefs and dispositions impact actions (Schussler et al., 2008; Splitter, 2010). As sustainability demands transformation, a new paradigm of thinking and acting promotes "a catalytic change for sustainability" where teachers are aware of their beliefs and practices (El-Deghaidy, 2012, p. 25). This study illustrates a case in which prospective teachers who demonstrate appropriate dispositions have decided to integrate theory into their practice. For example, the entrance interviews indicated participants exhibited initial acuity towards cultural dispositions and had a genuine desire to teach in a CLD school environment. Figure 2 provides a visual representation of our findings. Participants entered the program with experiences, preconceived notions and other environmental inputs. They also entered with an awareness of differences in themselves and the students they would be serving, an awareness of "the other". As we engaged participants in various literatures, workshops and conferences, they had an increased awareness of their own differences and the power they had to impact change for their diverse students.

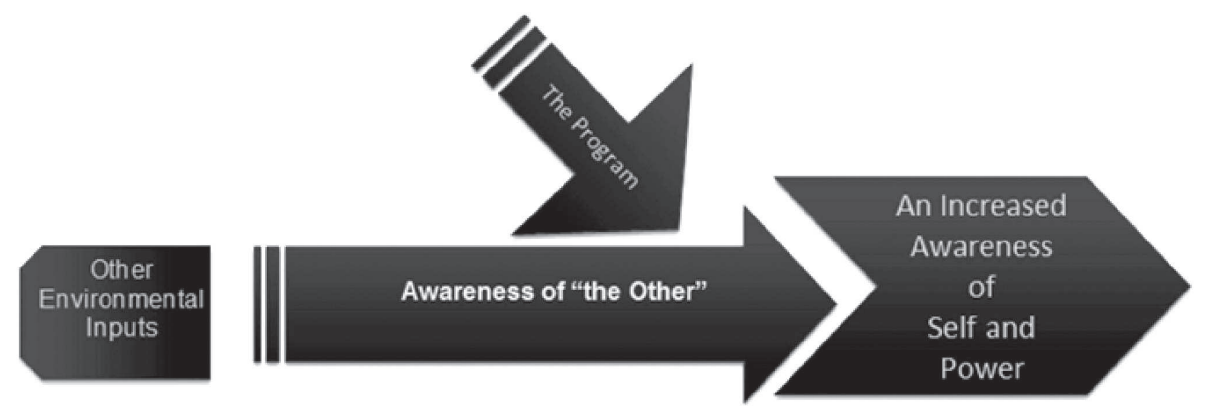

Figure 2. Visual Representation of Findings 
The results of this study will benefit those engaged in teacher education. It will provide a venue for further discussions on the importance of integrating the development of culturally responsive pedagogy and dispositions into the teacher's professional practice and fostering teacher education for sustainability (Strode, 2015). It is well documented that cultural relevance and responsiveness makes a difference (Ladson-Billings, 1994; Gay, 2000) and cultural dispositions are effective tools for sustainable development (Salomäki, Ruokonen, \& Ruismäki, 2012). Preparing teachers who are culturally competent assists in ensuring that all students reach their full potential academically (Aceves \& Orosco, 2014).

With regard specifically to the teaching of mathematics, culturally competent teachers have the dispositions, knowledge, and skills to support sustainable development by creating a mathematics learning environment where teacher planning and instructional practice draw on the diverse knowledge and experiences of the learners. This practice ensures cultural and linguistic inclusion, fosters pride among learners in their own cultural heritage, and improves academic learning (McKeown, 2011). When creating this type of mathematics learning environment, a culturally competent teacher understands that there are multiple perspectives on mathematical knowledge and challenges learners to think critically about these varying perspectives in order to address local and global issues (McKeown, 2013). Linguistic and cultural dispositions play an important role in sustainable development. If linguistically and culturally diverse students are to gain the confidence and skills they will need to move forward to a more advanced study of mathematics and throughout their lives, mathematics teachers must have the cultural dispositions that supports a high quality education for students from CLD backgrounds, while promoting and preserving their cultural heritage.

At the submission of this manuscript, four of the five participants are working in CLD settings, of which one teaches sheltered EL mathematics. These participants have taught in diverse environments for five years, thus demonstrating sustainability. The fifth participant has left the profession, stating lack of support from administration. She taught in a school that did not have a varied cultural or linguistics student population. As a result of the current status of our participants' sustainability, we recommend future research to examine how these culturally dispositions are reflected in practice.

\section{References}

Aceves, T. C., \& Orosco, M. J. (2014). Culturally responsive teaching (Document No. IC-2). Retrieved from the University of Florida, Collaboration for Effective Educator Development, Accountability, and Reform Center website Retrieved May 10, 2015, from: http:/ceedar.education.ufl.edu/tools/innovation-configurations/

Allchin, D. (1999). Science and values: An educational perspective. Science and Education, 8(1), 1-12.

Allexsaht-Snider, M., \& Hart, L. E. (2001). "Mathematics for all”: How do we get there? Theory into Practice, 40(2), 93-101.

Aplin, N., \& Saunders, J. (1996, March). Values and value priorities of Singaporean and Australian swimmers [Online]. Australian Association for Research in Education.

Arias, M., \& Poynor, L. (2001). A good start: A progressive, transactional approach to diversity in preservice teacher education. Bilingual Research Journal 25(4), 417434. 
Banks, J. A., \& Banks, C. M. (2009). Multicultural education: Issues and perspectives. Indianapolis, IN: Wiley.

Banks, J., Cochran-Smith, M., Moll, L., Richert, A., Zeichner, K., LePage, P., \& McDonald, M. (2005). Teaching diverse learners. In L. Darling-Hammond \& J. Bransford (Eds.), Preparing teachers for a changing world: What teachers should learn and be able to do (pp. 232-274). San Francisco, CA: Jossey-Bass.

Bennett, C. S. (2008). Attachment-informed supervision for social work field education. Clinical Social Work Journal, 36, 97-107. doi 10.1007/s10615-007-0135-z

Bishop, A. J. (1988). Mathematical enculturation: A cultural perspective on mathematics education. Dordrecht, The Netherlands: Kluwer Academic Publishers.

Bishop, A. J., FitzSimons, G. E., Seah, W. T., \& Clarkson, P. C. (1999). Values in mathematics education: Making values teaching explicit in the mathematics classroom. Paper presented at the Australian Association for Research in Education, Melbourne.

Blanchett, W. J. (2006). Disproportionate representation of African American students in special education: Acknowledging the role of white privilege and racism. Educational Researcher, 35(6), 24-28.

Boaler, J. (2002). The development of disciplinary relationships: Knowledge, practice, and identity in mathematics classrooms. For the Learning of Mathematics, 22(1), $42-47$.

Council for the Accreditation of Educator Preparation. (2013). CAEP standards for accreditation of educator preparation. Retrieved April 19, 2015, from: http://www. caepsite.org/standards.html

Culture (2016). In Merriam-Webster.com. Retrieved April 1, 2015, from: http://www. merriam-webster.com/dictionary/culture

D'Ambrosio, U. (2001). Mathematics and peace: A reflection on the basis of western civilization. Leonardo, 34(4), 327-3.

Darling-Hammond, L., \& Bransford, J. (2007). Preparing teachers for a changing world: What teachers should learn and be able to do. New York, NY: Wiley \& Sons.

Dee, J. R., \& Henkin, A. B. (2002). Assessing dispositions toward cultural diversity among preservice teachers. Urban Education, 37(1), 22-44.

Dewey, J. (1933). How we think: A restatement of the relation of reflective thinking to the educative process. Boston, MA: D.C. Heath.

Edwards, S. (2011). Developing diversity dispositions for white culturally responsive teachers. Action in Teacher Education, 33(5/6), 493-508.

El-Deghaidy, H. (2012). Education for sustainable development: Experiences from action research with science teachers. Discourse and Communication for Sustainable Education, 3(1), 23-40. doi: 10.2478/v10230-012-0002-1

Garcia, E., Arias, M. B., Harris Murri, N. J., \& Serna, C. (2010). Developing responsive teachers: A challenge for a demographic reality. Journal of Teacher Education, 61(1-2), 132-142.

Gay, G. (2000). Culturally responsive teaching: Theory, research, and practice. New York, NY: Teachers College Press.

Gerretson, H., Iliško, Dz., \& Fortono, C. (2010). Sustaining self-regulated students' learning through inquiry-driven mathematics and science instruction. Discourse and Communication for Sustainable Education, 1(1),3-17. 
Gershenson, S., Holt, S., \& Papageorge, N. (2016). Who believes in me? The effect of student-teacher demographic match on teacher expectations. Economics of Education Review, 52, 209-224.

Giles, M. B., \& Sherman, T. M. (1982). Measurement of multicultural attitudes of teacher trainees. Journal of Educational Research, 75(4), 205-209.

Gillette, M., \& Boyle-Baise, M. (1995, April). Multicultural education at the graduate level: Assisting teachers in developing multicultural perspectives. Paper presented at the annual meeting of the American Education Research Association, San Francisco, CA.

Greenberg, J., McKee, A., \& Walsh, K. (2013). Teacher prep review: A review of the nation's teacher preparation programs. Washington, DC: National Council for Teacher Quality.

Grootenboer, P. (2010). Primary teachers' affective development in mathematics: Developing positive beliefs, attitudes and feelings. Saarbrücken, German: Lambert Academic Publishing.

Guthrie, J. T., Wigfield, A., \& VonSecker, C. (2000). Effects of integrated instruction on motivation and strategy use in reading. Journal of Educational Psychology, 92(2), 331-341.

Haberman, M. (1991a). Can cultural awareness be taught in teacher education programs? Teaching Education, 4(1), 25-31.

Haberman, M. (1991b). The rationale for training adults as teachers. In C. Sleeter (Ed.), Empowerment through multicultural education (pp. 275-286). Albany, NY: State University of New York Press.

Haberman, M. J., \& Post, L. (1992). Does direct experience change education students' perceptions of low-income minority students. Midwestern Educational Researcher, 5(2), 29-31.

Haberman, M. (1995). Star teachers of children in poverty. Indianapolis, IN: Kappa Delta Pi.

Haberman, M. (1996). Selecting and preparing culturally competent teachers for urban schools. In J. Sikula (Ed.), Handbook of research on teacher education (pp. 747760). New York, NY: Macmillian.

Harrison, N. (2008). Engaging identities in a regional university classroom. Higher Education, (56), 241-258.

Hayes, C., \& Juárez, B. (2012). There is no culturally responsive teaching spoken here: A critical race perspective. Democracy \& Education, 20(1), 1-14.

Herzig, A. H. (2004), Becoming mathematicians: women and students of color choosing and leaving doctoral mathematics. Review of Educational Research, (74), 171214.

Ingersoll, R., Merrill, L., Stuckey, D. (2014). Seven trends: The transformation of the teaching force, updated April 2014. CPRE Report (\#RR-80). Philadelphia: Consortium for Policy Research in Education, University of Pennsylvania.

Irvine, J. J. (1990). Black students and school failure: Policies, practices, and prescriptions. New York: Greenwood Press.

Jenks, C., Lee, J. O., \& Kanpol, B. (2001). Approaches to multicultural education in preservice teacher education: Philosophical frameworks and models for teaching. Urban Review, 33(2), 87-105. 
Jones, T. G., \& Fuller, M. L. (2003). Teaching Hispanic children. Boston, MA: Allyn \& Bacon.

Kabadayi, A. (2015). Analyzing prospective preschool teachers' reasons and motives for entering a teaching career. Didactica Slovenica, 30(2), 103-122.

Kaplan, L., \& Edelfelt, R. (Eds.). (1996). Teachers for a new millennium: Aligning development, national goals, and high standards for all students. Thousand Oaks, CA: Corwin Press.

Kersaint, G., Thompson, D. R., \& Petkova, M. (2009). Teaching mathematics to English language learners. New York, NY: Routledge.

Ladson-Billings, G. (1994). Dreamkeepers: Successful teachers of African American children. San Francisco, CA: Jossey-Bass, Inc.

Larke, P. J. (1988). Cultural diversity awareness inventory: Assessing the sensitivity of preservice teachers. Action in Teacher Education, 12, 23-30.

Lee, M. J., \& Cockman, M. J. (1995). Values in children's sport: Spontaneously expressed values among young athletes. International Review for the Sociology of Sport, 30, 337-352.

Lucas, T. Villegas, A. M., \& Freedson-Gonzalez, M. (2008). Linguistically responsive teacher education: Preparing classroom teachers to teach English language learners. Journal of Teacher Education, 59(4), 361-373.

McKeown, R. (2013). Teaching for a brighter more sustainable future. Kappa Delta Pi Record, 49(1), 12-20.

McKeown, R. (2011). Using rubrics to assess student knowledge related to sustainability: A practitioners' view. Journal of Education for Sustainable Development, 5(1), 61-74.

Merriam, S. B. (2001). Qualitative research and case study applications in education. San Francisco, CA: Jossey-Bass.

Mertler, C. A., \& Charles, C. M. (2001). Introduction to education research (7 ${ }^{\text {th }}$ Ed.). Boston, MA: Pearson.

Nasir, N.S., \& Cobb, P. (2002). Introduction to the special issue "diversity, equity and mathematical learning." Mathematical Thinking and Learning, 4(2/3), 91-102.

National Assessment of Educational Progress. (2015). Mathematics and reading assessments. NCES No. 2015136. Washington, DC: US Department Education. Release date October 28, 2015.

National Center for Education Statistics. (1999). Teacher quality: A report on the preparation and qualification of public school teachers. NCES No. 1999080. Washington, DC: U.S. Department of Education.

National Center for Education Statistics. (2016). The Condition of Education 2016, NCES No. 2016144. Washington, DC: US Department of Education.

National Council for Accreditation of Teacher Education. (2007). NCATE defines dispositions as used in teacher education. Retrieved December 10, 2011, from: http://www.ncate.org/Public/Newsroom/NCATENewsPressReleases/tabid/669/ EntryId/55/NCATE-Defines-Dispositions-as-used-in-Teacher-Education-IssuesCall-to-Action.aspx

National Council of Teachers of Mathematics. (1991). Professional standards for teaching mathematics. Reston, VA. Author.

National Council of Teachers of Mathematics. (2000). Principles and standards for school mathematics. Reston, VA. Author. 
Nespor, J. (1987). The role of beliefs in the practice of teaching. Journal of Curriculum Studies, 19, 317-328.

Paige, R. M. (1993). On the nature of intercultural experiences and intercultural education. In R.M. Paige (Ed.), Education for the intercultural experience (pp. 1-20). Yarmouth, ME: Intercultural Press.

Rios, F. (1996). Teacher thinking in cultural contexts. Albany, NY: State University of New York Press.

Rokeach, M. (1968). Belief, attitudes, and values: A theory of organization and change. San Francisco, CA: Jossey-Bass.

Ryan, R, \& Deci, E. (2000). Intrinsic and extrinsic motivations: Classic definitions and new directions. Contemporary Educational Psychology, 25, 54-67. doi:10.1006/ ceps.1999.1020

Salomäki, U., Ruokonen, I., \& Ruismäki, H. (2012). Educators’ professional and personal growth: A case study of European teachers' in-service training courses. Journal of Teacher Education for Sustainability, 14(1), 20-29. doi: 10.2478/v10099-012-0002-z

Schoenfeld, A. H. (2002) Making mathematics work for all children: Issues of standards, testing, and equity. Educational Researcher, 31(1), 13-25. doi:10.3102/0013189X 031001013

Schussler, D. L., Bercaw, L. A., \& Stooksberry, L. M. (2008a). The fabric of teacher candidates' dispositions: What case studies reveal about teacher thinking. Action in Teacher Education, 29(4), 39-52.

Schussler, D. L., Bercaw, L. A., \& Stooksberry, L. M. (2008b). Using case studies to explore teacher candidates' intellectual, cultural, and moral dispositions. Teacher Education Quarterly, Spring, 105-122.

Short, D., \& Fitzsimmons, S. (2007). Double the work: Challenges and solutions to acquiring language and academic literacy for adolescent English language learners A report to Carnegie Corporation of New York. Washington, DC: Alliance for Excellent Education.

Shulman, L. S. (1987). Knowledge and teaching: Foundations of the new reform. Harvard Educational Review, February, 1-22.

Splitter, L. (2010). Disposition in education: Nonentities worth talking about. Educational Theory, 60(2), 203-230.

Stooksberry, L. M, Schussler, D., \& Bercaw, L. A. (2009). Conceptualizing dispositions: Intellectual, cultural, and moral domains of teaching. Teachers and Teaching: Theory and Practice, 15(6), 719-736.

Strauss, A. \& Corbin, J. (1990). Basics of qualitative research: Grounded theory procedures and techniques. Newbury Park, CA: Sage Publications.

Strode, A. (2015). Participatory action research for development of prospective teachers' professionality during their pedagogical practice. Discourse and Communication for Sustainable Education, 4(1), 80-90. doi: 10.2478/dcse-2013-0007

Villegas, A. M. (2007). Dispositions in teacher education: A look at social justice. Journal of Teacher Education, 58(5), 370-380.

Wenger, E. (1998). Communities of practice: Learning, meaning, and identity. Cambridge, MA: Cambridge University Press.

Yeung, A. S. W. (2006). Teachers' conceptions of borderless: A cross-cultural study on multicultural sensitivity of the Chinese Teachers. Educational Research for Policy and Practice, 5, 33-53. 


\section{Author Note}

This research was supported in part by a grant from the National Science Foundation: Robert Noyce Teacher Scholarship Program, Grant \# 0934791.

Correspondence concerning this article should be addressed to Desha Williams, Department of Secondary \& Middle Grades Education, Kennesaw State University, 580 Parliament Garden Way, MD 0122, Kennesaw, GA 30411. Email: dwill178@kennesaw.edu; 470-578-2505. 